\title{
The Novel Lipopeptide Poaeamide of the Endophyte Pseudomonas poae RE*1-1-14 Is Involved in Pathogen Suppression and Root Colonization
}

\author{
Christin Zachow, ${ }^{1}$ Ghazaleh Jahanshah, ${ }^{2}$ Irene de Bruijn, ${ }^{3}$ Chunxu Song, ${ }^{3}$ Federica lanni, ${ }^{4}$ \\ Zoltán Pataj, ${ }^{4}$ Heike Gerhardt, ${ }^{4}$ Isabelle Pianet, ${ }^{5}$ Michael Lämmerhofer, ${ }^{4}$ Gabriele Berg, ${ }^{6}$ Harald Gross, ${ }^{2}$ \\ and Jos M. Raaijmakers ${ }^{3}$

\begin{abstract}
${ }^{1}$ Austrian Centre of Industrial Biotechnology (ACIB GmbH), $8010 \mathrm{Graz}$, Austria; ${ }^{2}$ Pharmaceutical Institute, Department of Pharmaceutical Biology, University of Tübingen, 72076 Tübingen, Germany; ${ }^{3}$ Department of Microbial Ecology, Netherlands Institute of Ecology (NIOO-KNAW), Droevendaalsesteeg 10, 6708 PB Wageningen, The Netherlands; ${ }^{4}$ Pharmaceutical Institute, Department of Pharmaceutical Analysis and Bioanalysis, University of Tübingen; ${ }^{5}$ CESAMO-ISM, UMR 5255, CNRS, Université Bordeaux I, 351 Cours de la Libération, F-33405 Talence, France; ${ }^{6}$ Institute of Environmental Biotechnology, Graz University of Technology, 8010 Graz, Austria
\end{abstract}

Submitted 3 March 2015. Accepted 5 March 2015.

\begin{abstract}
Endophytic Pseudomonas poae strain $\mathrm{RE} * 1-1-14$ was originally isolated from internal root tissue of sugar beet plants and shown to suppress growth of the fungal pathogen Rhizoctonia solani both in vitro and in the field. To identify genes involved in its biocontrol activity, RE*1-1-14 random mutagenesis and sequencing led to the identification of a nonribosomal peptide synthetase (NRPS) gene cluster predicted to encode a lipopeptide (LP) with a 10amino-acid peptide moiety. The two unlinked gene clusters consisted of three NRPS genes, designated poaA (cluster 1) and poaB and poaC (cluster 2), spanning approximately $33.7 \mathrm{~kb}$. In silico analysis followed by chemical analyses revealed that the encoded LP, designated poaeamide, is a structurally new member of the orfamide family. Poaeamide inhibited mycelial growth of $R$. solani and different oomycetes, including Phytophthora capsici, $P$. infestans, and Pythium ultimum. The novel LP was shown to be essential for swarming motility of strain RE*1-1-14 and had an impact on root colonization of sugar beet seedlings The poaeamide-deficient mutant colonized the rhizosphere and upper plant cortex at higher densities and with more scattered colonization patterns than the wild type. Collectively, these results indicate that Pseudomonas poae $\mathrm{RE}^{*} 1-1-14$ produces a structurally new LP that is relevant for its antagonistic activity against soilborne plant pathogens and for colonization of sugar beet roots.
\end{abstract}

The species Pseudomonas poae was first described for a strain from the phyllosphere of Poa spp. (Behrendt et al. 2003). P. poae strain RE*1-1-14 was isolated from the internal part of sugar beet roots and was characterized as an antagonist of the soilborne pathogen Rhizoctonia solani (teleomorph: Thanatephorus cucumeris (A. B. Frank) Donk), the causal agent of damping-off and root rot disease of sugar beet (Zachow et al. 2008). Strain RE*1-1-14 promoted the growth of sugar beet and lettuce plants, and showed cultivar-dependent

Corresponding author: C. Zachow; E-mail: christin.zachow@tugraz.at

*The $\boldsymbol{e}$-Xtra logo stands for "electronic extra" and indicates that 23 supplementary figures and 4 supplementary tables are published online.

@ 2015 The American Phytopathological Society colonization patterns in sugar beet (Zachow et al. 2010). The composition of root exudates is different between Rhizoctoniatolerant and -susceptible sugar beet cultivars (Mark et al. 2005), therefore potentially attracting different beneficial microbes, which could explain the different colonization patterns. Differences between cultivars in the intimate microbe-plant interaction have also been observed in maize, rice, and wheat and correlated to the efficacy to control pathogens and to promote plant growth (Meyer et al. 2010; Peiffer et al. 2013). The underlying mechanisms, however, are less understood.

To better understand the host colonization and interplay between endophytic strain RE*1-1-14 and sugar beet plants, the RE*1-1-14 genome was recently sequenced and compared with other available Pseudomonas genomes (Müller et al. 2013). $P$. poae RE*1-1-14 was placed in the $P$. fluorescens subgroup with a high level of similarity to $P$. trivialis (Mulet et al. 2010). Comparison of the whole RE*1-1-14 genome sequence with the sugar-beet-associated strain $P$. fluorescens SBW25 (Rainey and Bailey 1996) showed a core genome of 4,242 genes and 555 unique genes for RE*1-1-14. The genome sequence further showed that strain $\mathrm{RE}^{*} 1-1-14$ is equipped with a set of genes which may contribute to the colonization of the rhizosphere and endosphere (Müller et al. 2013). These include genes for type three secretion systems, exoenzymes, and secondary metabolites, including a putative lipopeptide (LP). Within the P. fluorescens subgroup, the capacity to efficiently colonize plant surfaces is a key trait of biological control strains next to the production of antimicrobials (Raaijmakers and Mazzola 2012). For some Pseudomonas strains, LP contribute to colonization of plant root or leaf surfaces (Raaijmakers et al. 2010). For endophytic bacteria, however, little is known about the production of LP and their role in plant colonization.

In this study, we present the in silico analysis of nonribosomal peptide synthetase (NRPS) gene clusters in $P$. poae RE*1-1-14 encoding a putative LP. Structure predictions and chemical analyses of the purified LP led to the identification of a structurally novel cyclic lipodecadepsipeptide, designated poaeamide. Phenotypic comparisons of the wild type and poaeamide-deficient mutants revealed its contribution to swarming motility and antagonistic activity. In ad planta experiments, bacterial colonization of the root surfaces and cortex by $P$. poae RE*1-1-14 was analyzed by confocal 
laser-scanning microscopy (CLSM) for two sugar beet cultivars to determine the role of the LP poaeamide in ectophytic and endophytic colonization.

\section{RESULTS}

\section{Identification of the poaeamide gene cluster} in $P$. poae $\mathrm{RE}^{*}$ 1-1-14.

The complete genome sequence of $P$. poae $\mathrm{RE}^{*} 1-1-14$ was investigated for the presence of NRPS genes involved in LP biosynthesis. This resulted in the identification of 15 genes annotated as NRPS encoding. Nine genes had identity scores of at least $84 \%$ in a BlastP comparison with NRPS genes from seven other Pseudomonas strains. A putative LP gene cluster with three genes, designated poaA, poaB, and poaC, was identified in the genome of $P$. poae $\mathrm{RE}^{*} 1-1-14$ and further analyzed (Fig. 1). Inspection of the flanking regions of the poaeamide genes revealed two macrolide-specific efflux proteins downstream of poaC and LuxR-type regulatory genes upstream of poaA and downstream of poaC (Fig. 1).

Bioinformatic analyses revealed that the predicted PoaA, PoaB, and PoaC comprise two, four, and four modules, respectively, each consisting of a condensation (C), adenylation (A), and thiolation (T) domain. A tandem thioesterase (TE) domain was located at the carboxy terminal of PoaC. This architecture strongly resembles the OfaA-OfaB-OfaC biosynthetic system from $P$. protegens $\mathrm{Pf}-5$ (formerly $P$. fluorescens Pf-5), which is known to assemble the LP orfamide (Gross et al. 2007). In silico analysis of the A domain selectivity was performed to predict the amino acid composition of the peptide moiety (Ansari et al. 2004; Blin et al. 2013; Challis et al. 2000; Stachelhaus et al. 1999). Because genus-dependent deviations of the well-known A domain specificity code are empirically given (Bode 2009; Kalb et al. 2013; Li et al. 2013), we complemented the analysis with a phylogenetic approach in which all A domains were compared with those of functionally characterized NRPS systems from pseudomonads coding for LP (Fig. 2). Application of both approaches suggested that the peptide moiety of poaeamide possessed the amino acid sequence Leu-Glu-ThrLeu-Leu-Ser-Leu-Leu-Ser-Ile (Fig. 1). Hence, the predicted peptide sequence of poaeamide differs from orfamide $\mathrm{A}$ at amino acid 4 (Ile versus Leu) and 10 (Ile versus Val) and, thus, possibly represents a new member of the orfamide LP family (Fig. 1).

Next, all $\mathrm{C}$ domains were analyzed and classified regarding their subtype, both automated (Blin et al. 2013; Ziemert et al. 2012) and manually, using sequence motif- as well as phylogeny-based approaches. This analysis revealed that the $\mathrm{N}$-terminal $\mathrm{C}$ domain of PoaA represents a typical starter $\mathrm{C}$ domain $\left(\mathrm{C}_{\mathrm{s}}\right)$ (Supplementary Fig. S1), which acylates the first amino acid (here: L-Leu), usually with a 3-hydroxy (3OH) fatty acid (FA) (Imker et al. 2010; Kraas et al. 2010; Rausch et al. 2007). Of the remaining nine $C$ domains, two were identified as ${ }^{\mathrm{L}} \mathrm{C}_{\mathrm{L}}$ domains while seven $\mathrm{C}$ domains belong to the subtype of dual condensation/epimerization $(\mathrm{C} / \mathrm{E})$ domains. Combined $\mathrm{C} / \mathrm{E}$ domains were shown to catalyze epimerization reactions, which is inversion of the absolute configuration at one chiral center (i.e., in a NRPS context, the $\alpha-C$ atom of the amino acid that is loaded onto the $\mathrm{T}$ domain of the preceding module) (Balibar et al. 2005). Thus, the absolute configuration of the resultant peptide moiety could be theoretically deduced. Based on the fact that modules eight and nine contained either regular ${ }^{\mathrm{L}} \mathrm{C}_{\mathrm{L}}$ domains or a tandem TE domain, we hypothesize that Leu-7, Leu-8, and Ile-10 are L-configured. However, because several examples of $\mathrm{C} / \mathrm{E}$ domains have been reported in the literature where chemical analyses were not in agreement with the in silico predictions (de Bruijn et al. 2008; Gross et al. 2007; Rokni-Zadeh et al. 2012), the resultant absolute configuration can currently not be reliably predicted from $\mathrm{C} / \mathrm{E}$ domains and requires experimental validation.

Typical in Pseudomonas LP biosynthesis, a tandem of two distinct TE domains can be observed at the C-terminal end of the last NRPS of the cluster (Gross and Loper 2009). Phylogenetic analyses showed that the first TE domain of PoaC belongs to the subclass of type I TE domains (Hou et al. 2011; Roongsawang et al. 2007), particularly of those occurring in Pseudomonas cyclic LP (CLP) NRPS systems, which catalyze the intramolecular cyclization of LP between the C-terminal amino acid and a Thr or Ser residue (Lange et al. 2012) (Supplementary Fig. S2). The second TE domain of PoaC clearly clustered with type II TE domains, which are thought to act in cis or as a lone-standing $\mathrm{TE}$ in trans to deacylate misprimed $\mathrm{T}$ domains, thereby ensuring a continuous LP production (Hou et al. 2011; Schwarzer et al. 2002; Yeh et al. 2004). Considering the results of the TE domain analysis in combination with the predicted peptide sequence for poaeamide (Thr at AA3 and Ser at AA6), it was assumed that poaeamide represents a novel cyclic lipodecadepsipeptide, with either two or five exocyclic amino acids.

\section{Identification of $P$. poae mutants deficient in $L P$ production.}

To facilitate the identification of the product of the putative poaeamide gene cluster, mutants deficient in poaeamide production were required. Because LP production is usually linked to biosurfactant activity, a random plasposon-derived mutant library was generated and individually screened for loss of biosurfactant activity by the drop-collapse assay. Out of 2,020 random mutants, we isolated 15 putative LP-deficient mutants. Based on cloning and sequencing of the regions flanking the

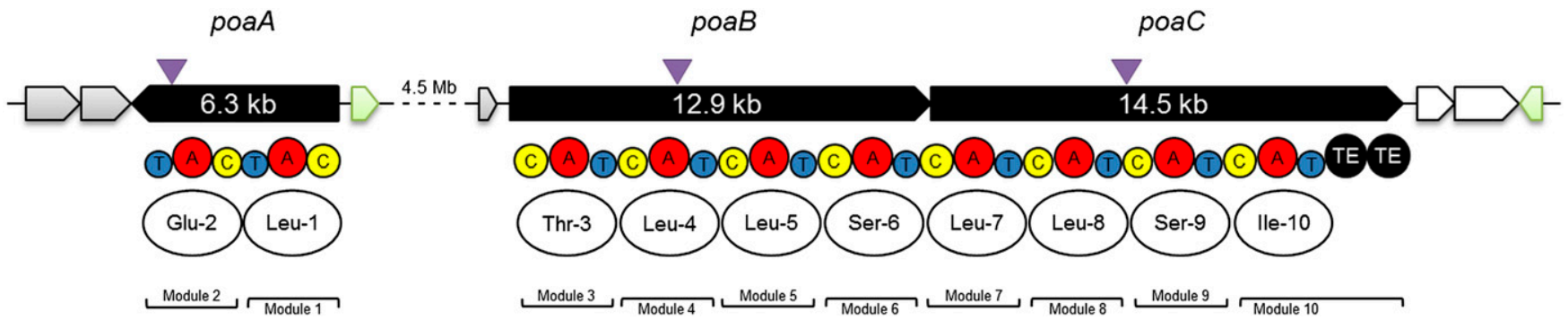

Fig. 1. Organization of the lipopeptide (LP) gene cluster identified in Pseudomonas poae RE*1-1-14 by in silico analysis of the genome sequence. Three genes are designated: poaA, poaB, and poaC (black); LuxR family transcriptional regulators (green); macrolide-specific ABC-type efflux carrier (white); and hypothetical proteins (gray). Underneath the genes is the module and domain organization of the nonribosomal peptide synthetases encoded by poaA, poaB, and poaC. The domains are labeled by $\mathrm{C}$, condensation; A, adenylation; T, thiolation; and TE, thioesterification. Underneath the domains are the amino acids predicted to be incorporated into the LP peptide moiety based on specific signature sequences in each A domain and subsequent phylogenetic analysis. The number associated with the amino acid refers to the position of the amino acid in the predicted LP peptide chain. Triangles represent the positions of the single transposon disruptions in the poaABC genes obtained by random mutagenesis. 
transposon insertion, an interruption in six different genes was found, with three genes disrupted in one of the three NRPS genes (poaA, poaB, or poaC). Southern hybridization showed that two (poaB::Tn5 and poaC::Tn5) of these three mutants contained a single transposon integration (Supplementary Fig. S3). The other gene interruptions occurred in genes for which the putative regulatory function in LP production is as yet unknown (Supplementary Table S1); for example, hisM, encoding the histidine transport system permease protein HisM; rec2, encoding a recombination protein that was also found as DNA internalization-related competence protein ComEC/Rec2 in P. fluorescens Pf0-1, P. protegens Pf-5, P. putida KT2440, and many other Pseudomonas genomes; and $y f h M$, encoding the uncharacterized lipoprotein YfhM that is known as an epoxide hydrolase in Bacillus subtilis (Huang et al. 1999).

\section{Isolation and structural analysis of poaeamide $A$.}

To identify the product of the poaeamide gene cluster, ethyl acetate extracts of the wild-type strain and the poaA::Tn5, poaB:: Tn5, and poaC::Tn5 mutants were prepared. Comparison of the metabolite profile by high-performance liquid chromatography (HPLC)-evaporative light scattering detector demonstrated that a group of three peaks (one main compound and two minor congeners) were present in the wild-type extract and absent in all three integration mutants (Supplementary Fig. S4). The major peak was tracked down in a large-scale cultivation batch $(400 \mathrm{ml}$ of resuspended cell cultures from 50 12-cm King's B agar plates) and led to the isolation of a pure compound at a yield of $2.4 \mathrm{~g}$, which was designated as poaeamide A.

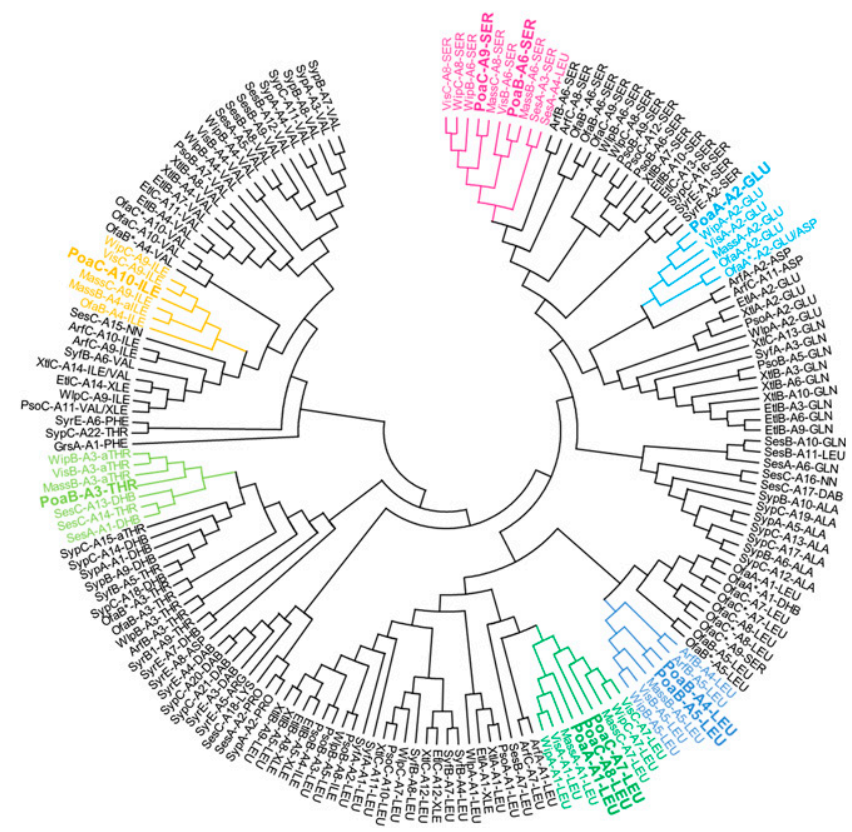

Fig. 2. Phylogenetic analysis of the A domains extracted from the modules of the CLP gene clusters encoding synthetases involved in arthrofactin (Arf, Pseudomonas sp. strain MIS38), entolysin (Etl, P. entomophila L48), massetolide (Mass, P. fluorescens SS101), orfamide (Ofa*, Pseudomonas sp. CMR12a; Ofa, $P$. protegens Pf-5), putisolvin (Pso, P. putida PCL1445), sesslin (Ses, Pseudomonas sp. CMR12a), syringafactin (Syf, P. syringae DC3000), syringopeptin (Syp, P. syringae pv. syringae B301D and B728a), syringomycin (Syr, P. syringae pv. syringae strain B301D), viscosin (Visc, P. fluorescens SBW25), white-line-inducing principle WLIP (Wip, P. fluorescens LMG 5329), white-line-inducing principle WLIP (Wlp, P. putida RW10S2), and xantholysin (Xtl, P. putida BW11M1) synthesis; and from the putative CLP clusters identified by the in silico analyses of $P$. poae RE*1-1-14 complete genome sequence. Nonprotein amino acids are annotated as follows: allo-threonine (aTHR), 2,3-dehydro-2-aminobutyric acid (DHB), 2,4-diaminobutyric acid (DAB), and not known (NN). Clusters comprising the CLP domains in P. poae RE*1-1-14 are highlighted in bold.
The major compound poaeamide A gave an $[\mathrm{M}+\mathrm{Na}]^{+}$peak at $\mathrm{m} / \mathrm{z} 1275.7805$ in the high-resolution electrospray ionization mass spectrometry (ESI-MS) (Supplementary Figs. S6 to S8), appropriate for a molecular formula of $\mathrm{C}_{61} \mathrm{H}_{108} \mathrm{~N}_{10} \mathrm{O}_{17}$ (calculated 1,275.7792, $\mathrm{D}+1.0 \mathrm{ppm})$. The ${ }^{1} \mathrm{H}$ nuclear magnetic resonance (NMR) spectrum of poaeamide A (Supplementary Figs. S10 and S11) was indicative for a LP by displaying exchangeable downfield amide signals ( $\delta_{\mathrm{H}}$ approximately 7.9 to 9.3$), \alpha$-proton resonances $\left(\delta_{\mathrm{H}}\right.$ approximately 3.8 to 4.6$)$, side chain protons $\left(\delta_{\mathrm{H}}\right.$ approximately 0.9 to 2.5 ), and several resonances characteristic for a FA moiety $\left(\delta_{\mathrm{H}} 0.9\right.$ and 1.4). Additional evidence for the peptidic nature of poaeamide $A$ was provided by the presence of carbonyl bonds in the ${ }^{13} \mathrm{C}$ NMR spectrum (Supplementary Fig. S12) ( $\delta_{C}$ approximately 171 to 181$)$ and characteristic IRbands at 3,290, 1,640, and 1,540 $\mathrm{cm}^{-1}$ (Supplementary Fig. S5). To acquire information regarding the building block composition and their connectivity, ESI tandem mass spectrometry experiments were carried out. For this analysis, the $[\mathrm{M}+\mathrm{Na}]^{+}$quasimolecular ion was collected and fragmented (Supplementary Figs. S7 and S9). The combination of $b$ and y fragments along with the associated dehydrated derivatives suggested the presence of the peptide sequence Xle-Glu-Thr-Xle-Xle-Ser-Xle-XleSer-Xle (Xle $=$ Leu or Ile) (Supplementary Table S2), which was in agreement with the proposed peptide sequence by bioinformatics (Fig. 3). Subtraction of the atoms accounted for the 10 identified amino acids from the molecular formula $\left(\mathrm{C}_{51} \mathrm{H}_{89} \mathrm{~N}_{10} \mathrm{O}_{15}\right)$ showed that the remaining fragment of this molecule had to contain 10 carbon and two oxygen atoms. This calculation, together with the observed fragment at $\mathrm{m} / \mathrm{z}, 308$ $[\mathrm{M}+\mathrm{Na}]^{+}$peak of $3 \mathrm{OH}-\mathrm{FA}-\mathrm{Leu}$, led to the hypothesis that a $3 \mathrm{OH}$-decanoic acid (3-HDA) was attached to the $\mathrm{N}$ terminus of the peptide sequence. The exact planar structure of poaeamide A was determined by further NMR experiments. In-depth interpretation of the one-dimensional NMR (Supplementary Figs. S10 to S13) $\left({ }^{1} \mathrm{H},{ }^{13} \mathrm{C}\right.$, and DEPT135) and twodimensional NMR spectra (Supplementary Figs. S14-S20) $\left({ }^{1} \mathrm{H}-{ }^{13} \mathrm{C}-\mathrm{HSQC},{ }^{1} \mathrm{H}-{ }^{13} \mathrm{C}-\mathrm{HSQC}-\mathrm{TOCSY},{ }^{1} \mathrm{H}-{ }^{1} \mathrm{H}-\mathrm{COSY}\right.$, and ${ }^{1} \mathrm{H}-{ }^{13} \mathrm{C}$ - and $\left.{ }^{1} \mathrm{H}-{ }^{15} \mathrm{~N}-\mathrm{HMBC}\right)$ defined and corroborated the presence of 10 individual amino acids $(5 \times$ Leu, $2 \times$ Ser, $1 \times$ Thr, $1 \times$ Glu, and $1 \times$ Ile) and one 3 -HDA residue (Supplementary Table S3; Supplementary Fig. S21). These subunits were connected using a combination of ${ }^{1} \mathrm{H}^{-}{ }^{13} \mathrm{C}-\mathrm{HMBC}$ correlations from the $\mathrm{NH}$ resonances to the amide carbonyls and observed $\mathrm{H}^{\alpha}(\mathrm{i}) \rightarrow \mathrm{H}^{\mathrm{N}}(\mathrm{i}+1)$ cross peaks in the ${ }^{1} \mathrm{H}-{ }^{1} \mathrm{H}-\mathrm{ROESY}$ spectrum to give the primary assembled linear sequence of poaeamide A. These residues accounted for 12 of the 13 double bond equivalents, indicating that the final degree of unsaturation must arise from poaeamide $\mathrm{A}$ having an overall cyclic constitution. A ${ }^{1} \mathrm{H}^{13} \mathrm{C}-\mathrm{HMBC}$ cross correlation, detected between the $\mathrm{C}$-terminal Ile-10 carbonyl atom and the $\beta$-proton of Thr- 3 demonstrated that the ring closure was formed between the Thr-3 side chain and the Ile-10 residue via a lactone bond. The resultant complete covalent structure of poaeamide $\mathrm{A}$ is shown in Figure 3.

\section{Absolute configuration of poaeamide A.}

Stereo-analysis of the 3-HDA of poaeamide A was accomplished by enantioselective HPLC-ESI-MS analysis, with Chiralpak ZWIX (+) as chiral stationary phase (Ianni et al. 2014 ), and found to be $R$-configured. The configuration of the amino acids was determined by enantioselective gas chromatography (GC)-MS analysis using Chirasil Val. Prior to analysis by GC-MS, samples were subjected to acidic hydrolysis and subsequent derivatization. Configurations were determined by comparison of retention time of the amino acids in the sample with those of authentic standards and found to be $1 \times \mathrm{L}$-Ile, $1 \times$ D-allo-Thr, $2 \times$ D-Ser, $1 \times$ D-Glu, $4 \times$ L-Leu, and $1 \times$ D-Leu 
(Supplementary Table S4). However, the position of the D-Leu residue within the peptide backbone was evident neither from these data nor from bioinformatics or NMR spectroscopic data. To clarify this unsolved question and, thus, to fully stereochemically characterize poaeamide A, we embarked on a twopronged partial degradation strategy. At first, enzymatic cleavage by pepsin was performed. However, peptide cyclization represents a protection mechanism and usually prevents enzymatic attacks. Hence, in order to guarantee better access of the enzyme, prior to enzymatic hydrolysis, compound poaeamide A was linearized by basic saponification of the lactone bond. After HPLC purification, the linear form was incubated with pepsin and the resultant major fragments were rechromatographed and analyzed by chiral GC-MS. Pepsin is known to cleave preferentially at the carboxyl side of L-Phe, L-Leu, and, to a lesser extent, L-Glu. The application of this enzymatic approach led to the conclusion that Leu-7 and Leu-8 were L-configured and that the D-Leu residue had to be located in the obtained 3-HDA-Leu1-Glu-2-Thr-3-Leu-4-Leu-5 subpeptide. Because D-configured amino acids are resistant to hydrolysis by endopeptidases, it was deduced from this peptide fragment that Leu-5 was also L-configured. In order to obtain complementary fragments, we then switched to a chemical partial degradation strategy using mild acid hydrolysis of poaeamide A. The chemical digestion yielded 3-HDA-Leu-1, with no detectable D-Leu. Location of D-Leu was finally determined, examining the configuration of the subpeptide Thr-3-Leu-4-Leu-5, which contained one $1 \times \mathrm{D}$-Leu and $1 \times \mathrm{L}$-Leu residue, hence indicating that Leu-4 was D-configured. The resultant complete stereo-structure of poaeamide A is shown in Figure 3.

\section{Biological activities of poaeamide.}

Antifungal and antioomycete activity. Surface tension measurements showed a response curve typical for lipopeptide surfactants and indicated that the critical micelle concentration (CMC) of reverse-phase (RP)-HPLC purified poaeamide is approximately $15 \mu \mathrm{g} \mathrm{ml}^{-1}$ (Supplementary Fig. S22A). Lysis of Phytophthora capsici and P. infestans zoospores occurred at concentrations above the CMC value of $50 \mu \mathrm{g} \mathrm{ml}^{-1}$ or higher (Supplementary Fig. S22B). Poaeamide caused immobilization and subsequent lysis of entire $P$. capsici and P. infestans zoospore populations within $1 \mathrm{~min}$, whereas cell-free culture supernatant of the poaeamide-deficient mutants did not cause these responses.

When $P$. capsici, $P$. infestans, Pythium ultimum, and $R$. solani were grown in direct contact with the poaeamide solution, an inhibitory effect was found in fresh weight (except for
Phytophthora infestans) and in dry weight of the mycelial biomass for all tested pathogens. A statistically significant reduction of the dry weight of mycelial biomass was found at $50 \mu \mathrm{g} \mathrm{ml}^{-1}$ for $R$. solani, P. capsici, and P. infestans and at $250 \mu \mathrm{g} \mathrm{ml}^{-1}$ for Pythium ultimum (Fig. 4).

Swimming, swarming, and biofilm formation. For several Pseudomonas strains, the involvement of LP in swarming, biofilm formation, regulation of attachment-detachment to and from surfaces, and root colonization has been reported (Loper et al. 2012; Pauwelyn et al. 2013; Raaijmakers et al. 2010). Soft agar assays showed that Pseudomonas poae RE*1-1-14 was able to swim and swarm on 0.2 and $0.6 \%$ soft agar, respectively (Fig. 5). The poaeamide-deficient mutants poaA::Tn5, poaB:: $\mathrm{Tn} 5$, and poaC::Tn5 were completely impaired in swarming motility, whereas swimming motility was partly impaired and showed a regular concentric growth around the initial inoculum (Fig. 5). The role of poaeamide in biofilm formation could not be determined for $P$. poae RE*1-1-14; no significant biofilm formation was observed for the wild-type strain in the in vitro assay. In a microtiter plate assay, neither the wild type nor the three poaeamide mutants produced significant biofilms compared with the reference strain $P$. fluorescens SS101 at temperatures from 15 to $30^{\circ} \mathrm{C}$ (Supplementary Fig. S23).

\section{The role of poaeamide in root colonization and endophytic behavior.}

The colonization patterns of wild-type $P$. poae $\mathrm{RE}^{*} 1-1-14$ and poaeamide-deficient mutants (poaA::Tn5, poaB::Tn5, and poaC:: Tn5) labeled with DsRed were monitored by dilution plating root suspension of 2-week-old roots cultivated in germination pouches and by confocal microscopy. The cell densities (CFU) of the wild type and mutants colonizing the whole root ranged from $\mathrm{CFU}$ $\log _{10} 5.0 \pm 0.2$ to $\mathrm{CFU} \log _{10} 6.3 \pm 0.3$ per gram of root fresh weight (Fig. 6A). The three mutants reached significantly higher densities than the wild-type strain in both the whole root (including the endo- and ectophytic microenvironments) (Fig. 6A) and the root cortex under the epidermal cell layer (Fig. 6B) of the $R$. solani-tolerant sugar beet 'Jenna' (except poaC::Tn5) (Fig. 6B). No differences were detected between the wild-type strain and all mutants of the $R$. solani-susceptible 'Beretta' for both the endo- and ectophytic parts.

Using CLSM, two types of colonization patterns were found for both the Rhizoctonia-susceptible Beretta and the tolerant Jenna. First, single cells and clusters were found in epidermal cell interstices following the root cells growth or in junctions to root hairs (Fig. 7, first and third column). Second, biofilm-like colonization covering the sugar beet root surface, interstices,

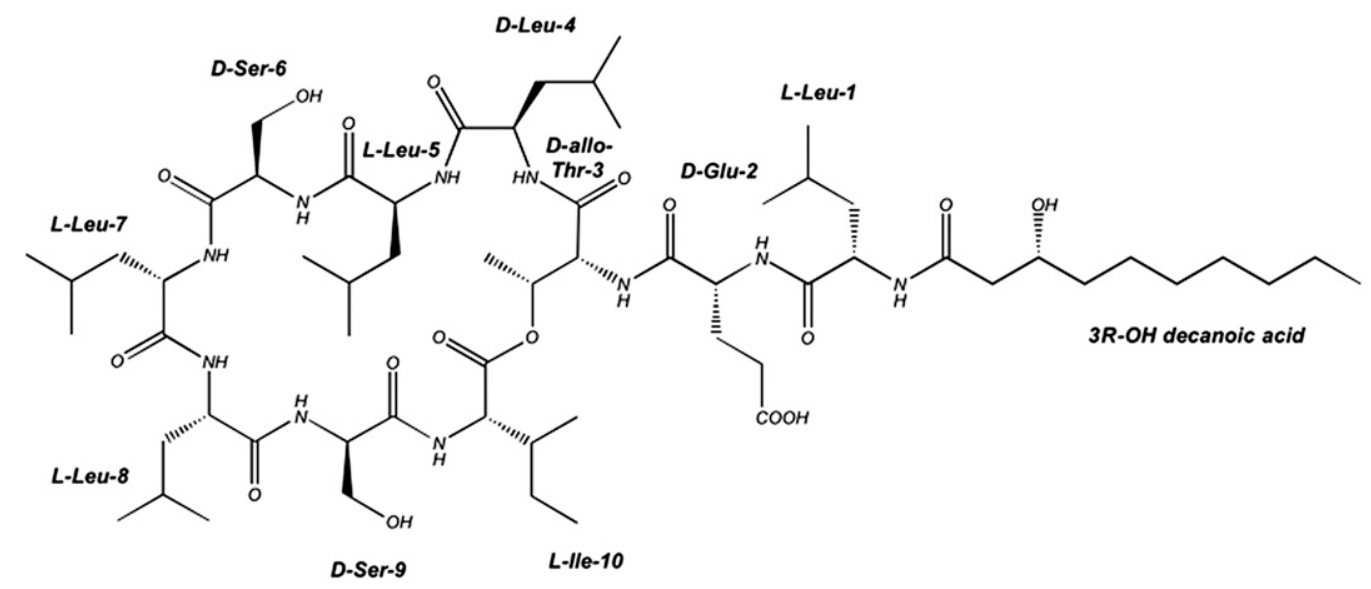

Fig. 3. Experimentally determined chemical structure of the main lipopeptide of Pseudomonas poae RE*1-1-14. 
and upper cortex under the layer of the epidermal cells was found in all treatments (Fig. 7, second and fourth column). No obvious differences in colonization were observed between the cultivars (Fig. 7). In comparisons between the wild type and the poaeamide-deficient mutants, the mutants showed less colonization compared with the wild type for both cultivars (Fig. 7, first and third column). Also, the structure of the presumed biofilms appeared different: in the wild-type biofilm, the cells clustered together and formed a dense carpet-like structure (Fig. 7B and D), whereas the mutant biofilms showed a loose arrangement and were found mainly in parts were the attachment of the cells was supported by other plant parts such as lateral roots, root hairs, and detached plant debris.

\section{DISCUSSION}

In this study, we identified the chemical structure and characterized the bioactivity of a structurally new LP, designated poaeamide, for endophytic $P$. poae RE*1-1-14. The poaeamide structure is similar to that of orfamides A to E produced by P. protegens Pf-5 (Loper and Gross 2007) and Pseudomonas sp. CMR12a (D'aes et al. 2014) (Table 1). However, poaeamide A differs from the orfamides A to $\mathrm{E}$ in the $3 \mathrm{OH}$ FA chain length, and the 4th and 10th amino acid residues of the peptide backbone.

\section{Genome mining approach.}

Poaeamide was identified employing a genome-driven approach. The peptide backbone of the poaABC gene cluster could be reliably deduced via A domain phylogeny analyses.
Further phylogenetic analyses, this time with the tandem TE domains, could readily narrow the cyclization pattern to two possibilities. However, whereas the two-dimensional structure of the peptide backbone now can be precisely determined for Pseudomonas NRPS systems, the prediction of the resulting absolute configuration still represents a challenge. Due to the presence of ${ }^{\mathrm{L}} \mathrm{C}_{\mathrm{L}}$ domains and the adjacent tandem TE domains, the stereochemistry of Leu-7, Leu-8, and Ile-10 was reliably predicted to be L-configured. However, concerning $\mathrm{C} / \mathrm{E}$ domains, a more complex picture emerges. The chemical analyses provided proof that only five of the seven $\mathrm{C} / \mathrm{E}$ domains present in poaABC are actually active. The dual $\mathrm{C} / \mathrm{E}$ domains of module 2 and 6 are obviously inactive and did not invert the absolute configuration of Leu-1 and Leu-5, respectively. The lack of prediction regarding $\mathrm{C} / \mathrm{E}$ domains is substantiated by the fact that the sequence motif that determines the activity is currently unknown. However, it is possible that $\mathrm{x}$-ray studies of active and inactive $\mathrm{C} / \mathrm{E}$ domains or every $\mathrm{C} / \mathrm{E}$ domain that is correlated with the corresponding resultant configuration will contribute to the understanding of the function and enable a prediction by bioinformatics in future.

\section{Origin of the gene cluster.}

From a chemical perspective, poaeamide A can be unambiguously classified as a member of the orfamide compound family. Based on this similarity, it can be envisioned that the substrate specificity of A domains of module 4 and 10, of an evolutionary preceding orfamide cluster, simply changed over time. However, notably a different picture emerges after

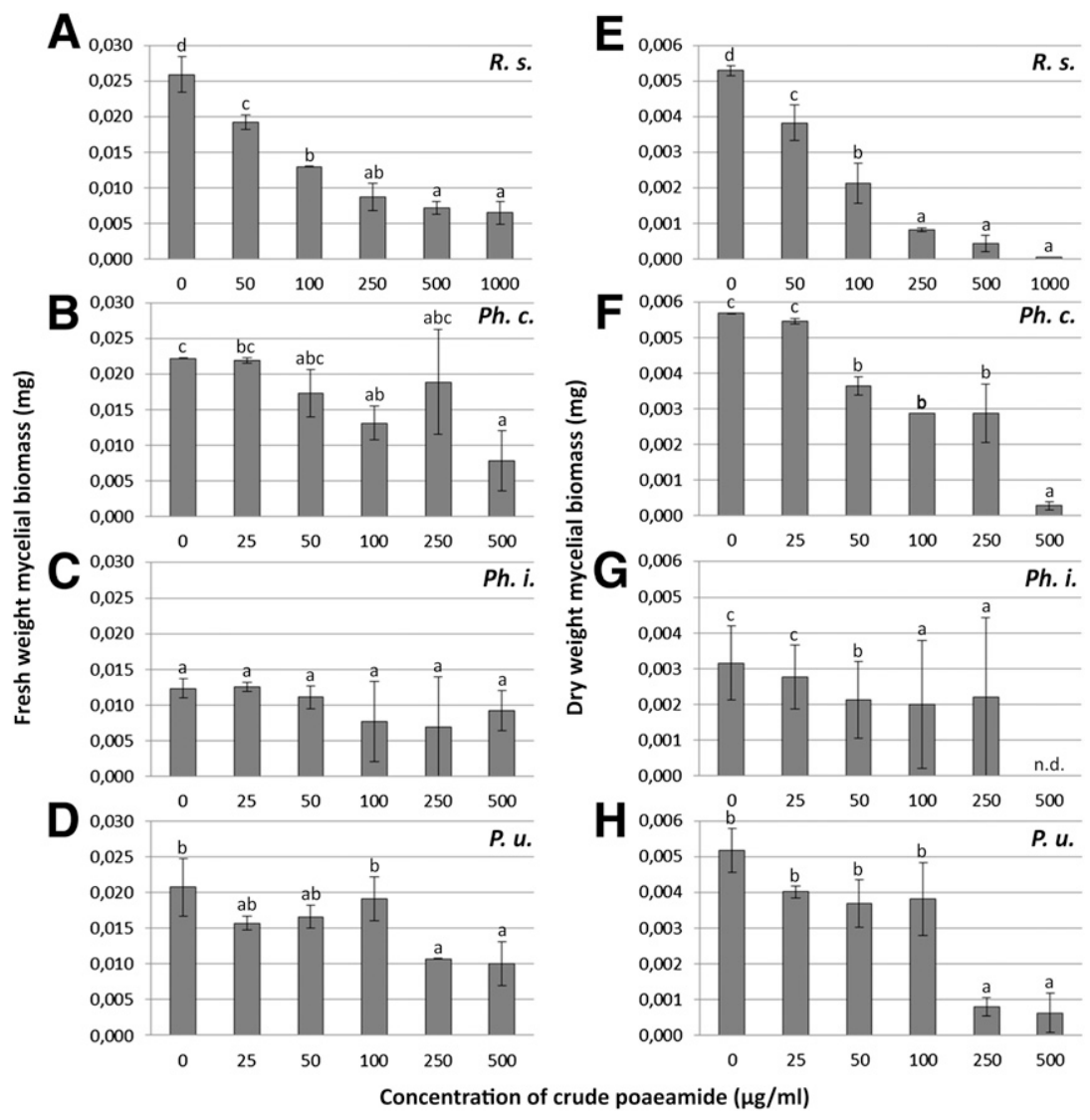

Fig. 4. Inhibitory effect of poaeamide of Pseudomonas poae RE*1-1-14 on A-D, fresh and E-F, dry weight of mycelium biomass. Fungal and oomycete plant pathogens were tested: A and E, Rhizoctonia solani (R. s.); $\mathbf{B}$ and F, Phytophthora capsici (Ph. c.); $\mathbf{C}$ and $\mathbf{G}$, Phytophthora infestans (Ph. i.); and D and $\mathbf{H}$, Pythium ultimum $($ P. и.). Cultures in six-well plates were amended with increasing concentrations of crude poaeamide dissolved in sterile distilled water. Mycelial biomass was measured after 2 days postinoculation. Mean values of four replicates are shown and error bars represent the standard errors. Different letters indicate significant differences $(P \leq 0.05)$; n.d. $=$ not determined. 
a comparison of the genetic backbone of the two known orfamide NRPS systems with the poaeamide gene cluster. Whereas genes coding for production of the 10 modules of orfamide A to E are organized in a single operon in the genomes of $P$. protegens Pf-5 and Pseudomonas sp. CMR12a, orthologs for the LP in P. poae RE*1-1-14 are arranged at two distinct locations in the genome. Such a physically disconnected NRPS gene architecture has been observed for the biosynthethic pathway for entolysin (P. entomophila L48) (Vallet-Gely et al. 2010), xantholysin A (P. putida BW11M1) (Li et al. 2013), and, particularly, for the synthesis of CLP of the viscosin family such as the eponymous compound viscosin ( $P$. fluorescens SBW25) (de Bruijn et al. 2007), massetolide A (P. fluorescens SS101) (de Bruijn et al. 2008), and white-line-inducing principle (WLIP) (Rokni-Zadeh et al. 2012). Phylogenetic comparison of each NRPS domain consistently points to evolutionary relatedness of the poaeamide system with those of the lipononadepsipeptides of the viscosin family. From Figure 2, it becomes apparent that all A domains of the poaeamide system cluster very closely with those of the viscosin/WLIP/massetolide systems, whereas the similarities to the A domains of the orfamide systems of Pseudomonas sp. CMR12a (D'aes et al. 2014) and P. protegens Pf-5 (Loper and Gross 2007) were less pronounced. The same tendency was found for the $\mathrm{C}$ and TE domains. Collectively, these observations suggest that the poaeamide gene cluster derived from the viscosin/WLIP/massetolide gene cluster rather than from orfamide systems. Most likely, during evolution, the trimodular visc C/wlpC/massC-like gene was extended by another leucinespecific NRPS module, leading to a tetramodular system coding in combination with the corresponding remaining NRPS genes (viscAB/wlpAB/mass $A B$ ) for a novel NRPS assembly line for the synthesis of a ring-extended viscosin-derivative.

\section{Regulation and transport.}

Compared with our understanding of the ever-growing number of structurally novel LP and their biosynthesis genes, knowledge about the genetic network involved in regulation remains limited. Recently, three genes were found in $P$. fluorescens for their regulatory role in LP biosynthesis, including phgdh encoding D-3-phosphoglycerate dehydrogenase, the heat shock proteinencoding $d n a K$, and the transmembrane regulatory gene $p r t R$, all three targeting the transcriptional repression of the LuxR-type regulator gene MassAR of massetolide biosynthesis in P. fluorescens SS101 (Song et al. 2014). The LuxR-type

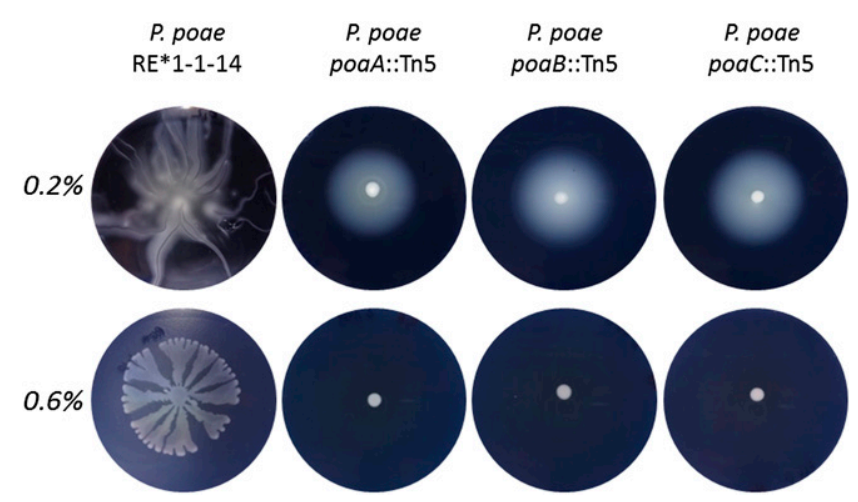

Fig. 5. Motility of Pseudomonas poae RE*1-1-14, lipopeptide-deficient mutants on $0.2 \%$ (swimming) and $0.6 \%$ (swarming) soft agar medium. Cell suspensions of the wild type and poaA::Tn5, poaB::Tn5, and poaC::Tn5 mutants were inoculated in the center of soft agar plates and incubated for $48 \mathrm{~h}$ at $25^{\circ} \mathrm{C}$. $P$. poae $\mathrm{RE}^{*} 1-1-14$ swims and swarms outward from the point of inoculation. The poaeamide-deficient mutants are partly impaired in motility when grown on $0.6 \%$ soft agar whereas, at $0.2 \%$, the mutants showed a diffuse halo-like swimming. regulators are often found flanking the biosynthetic genes, as in the $P$. poae $\mathrm{RE}^{*} 1-1-14$ genome: upstream of poaA and downstream of poaC (Fig. 1). LuxR-type regulators were described in similarly organized LP-biosynthesis systems in Pseudomonas spp. For example, the biosynthesis genes of orfamide in Pseudomonas sp. CMR12a are also flanked by two LuxR-type regulators. Also, the macrolide efflux proteins $\mathrm{MacA}$ and $\mathrm{MacB}$ have an arrangement in the poaeamide biosynthesis of $P$. poae RE*1-1-14 similar to that in orfamide and sessilin biosynthesis clusters of Pseudomonas sp. CMR12a (D'aes et al. 2014).

\section{Biological activity and biological role of poaeamide.}

LP produced by pseudomonads have diverse functions and activities, including a role in antimicrobial activity, swarming, biofilm formation, regulation of attachment-detachment to and from surfaces, and root colonization (Loper et al. 2012; Pauwelyn et al. 2013; Raaijmakers et al. 2010). Poaeamide exhibits zoosporicidal activity similar to that of viscosin (de Bruijn et al. 2007), massetolide A (De Souza et al. 2003), rhamnolipids (Kim et al. 2000), and orfamides (Gross et al. 2007). Comparable with other Pseudomonas LP, poaeamide is essential for surface motility. The poaeamide-deficient mutants lost their swarming ability, as was found for mutants in the biosynthesis of massetolide (de Bruijn et al. 2008), orfamide (D'aes et al. 2014), viscosin (de Bruijn et al. 2007), and WLIP (Rokni-Zadeh et al. 2012). The role of LP in biofilm formation can differ considerably between different strains and structurally different LP (Raaijmakers et al. 2010). Here, the role of poaeamide in biofilm formation could not be determined under the in vitro conditions tested.

$P$. poae RE*1-1-14 is known to be a good root colonizer, especially in Rhizoctonia-tolerant cultivars (Zachow et al. 2010). Cultivar-specific differences in colonization have also been reported for $P$. fluorescens $\mathrm{CHA} 0$ colonizing Swiss winter wheat (Triticum aestivum) 'Arina', 'Zinal', and 'Cimetta', which were able to accumulate naturally occurring plantbeneficial pseudomonads in the rhizosphere (Meyer et al. 2010). Our results showed that poaeamide mutants reached
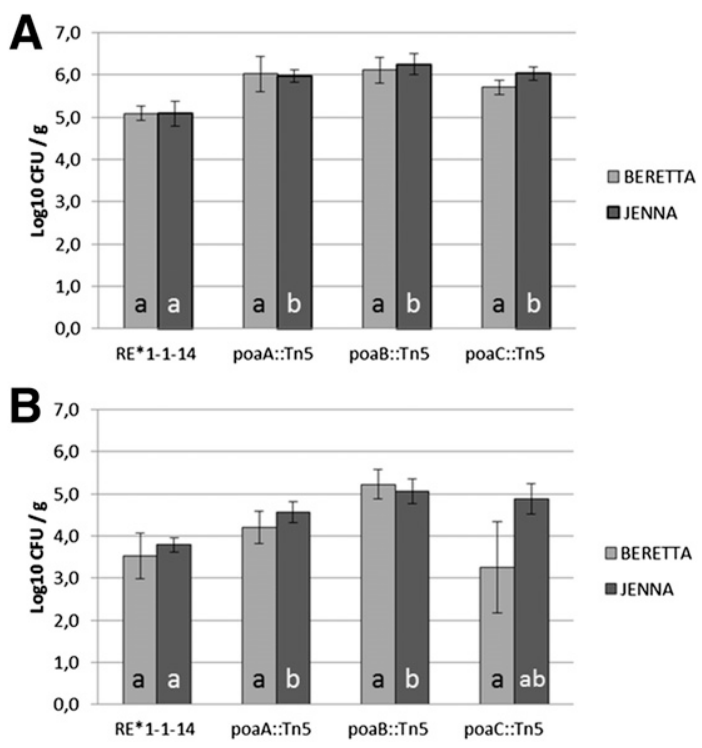

Fig. 6. Abundances of bacterial cells on the sugar beet seedlings Jenna (Rhizoctonia-tolerant) and Beretta (susceptible) cultivated in germination pouches for 2 weeks and inoculated with the Pseudomonas poae RE*1-1-14 wild type and the poaeamide-deficient mutants (poaA::Tn5, poaB::Tn5, and poaC::Tn5) colonizing $\mathbf{A}$, the whole root, including the endo- and ectophytic microenvironments; and $\mathbf{B}$, root cortex under the epidermal cell layer. $\log _{10}$ of CFU per gram root fresh weight was indicated. 
significantly higher densities than the wild-type strain in both the whole root (Fig. 6A) and the root cortex (Fig. 6B), especially for the tolerant Jenna. These results are in contrast to earlier studies that showed an advantage of LP in seed and root colonization. For example, in P. fluorescens SS101, the LP massetolide A was found to positively contribute to colonization of tomato roots (Tran et al. 2007). Also, for P. fluorescens DSS73, the LP amphisin contributed to the colonization of sugar beet seed and roots (Nielsen et al. 2005). For B. subtilis
6051, the LP-deficient mutant M1 showed smaller patches on Arabidopsis roots compared with the wild type (Bais et al. 2004). In the study by Kruijt et al. (2009), however, no differences in colonization abilities of $P$. putida strain 267 and its putisolvin-deficient mutant EP1 were observed. The authors concluded that, at least for cucumber plants, putisolvin-like surfactants do not contribute to rhizosphere competence.

Compared with other studies, our contrasting results regarding absolute cell counts can be resolved from the perspective of

Table 1. Fatty acid (FA) residue and amino acid (AA) arrangement of the 10 modules containing nonribosomal peptide synthetase (NRPS) genes of Pseudomonas protegens Pf-5 (orfamides A-C) (Gross and Loper 2009), Pseudomonas sp. CMR12a (orfamides D and E, D'aes et al. 2014), P. poae RE*1-1-14 (poaeamide A), and the nine modular NRPS genes of P. fluorescens SBW25 (viscosin) (de Bruijn et al. 2007) and P. fluorescens SS101 (massetolide A) (de Bruijn et al. 2008) $)^{\mathrm{a}}$

\begin{tabular}{|c|c|c|c|c|c|c|c|c|c|c|c|}
\hline Name & FA & AA1 & AA2 & $\mathbf{A A 3}$ & AA4 & AA5 & AA6 & $\mathbf{A A} 7$ & AA8 & AA9 & AA10 \\
\hline Orfamide A & $3 \mathrm{OH}-\mathrm{C} 14$ & Leu & Glu & Thr & Ile & Leu & Ser & Leu & Leu & Ser & Val \\
\hline Orfamide B & $3 \mathrm{OH}-\mathrm{C} 14$ & Leu & Glu & Thr & Val & Leu & Ser & Leu & Leu & Ser & Val \\
\hline Orfamide C & $3 \mathrm{OH}-\mathrm{C} 12$ & Leu & Glu & Thr & Ile & Leu & Ser & Leu & Leu & Ser & Val \\
\hline Orfamide D & $3 \mathrm{OH}-\mathrm{C} 12$ & Leu & Glu & Thr & Val & Leu & Ser & Leu & Leu & Ser & Val \\
\hline Orfamide E & 3OH-C14:1 & Leu & Glu & Thr & Val & Leu & Ser & Leu & Leu & Ser & Val \\
\hline Poaeamide A & 3ОН-С10 & Leu & Glu & Thr & Leu & Leu & Ser & Leu & Leu & Ser & Ile \\
\hline Viscosin & $3 \mathrm{OH}-\mathrm{C} 10$ & Leu & Glu & Thr & Val & Leu & Ser & Leu & Ser & Ile & $\ldots$ \\
\hline Massetolide A & $3 \mathrm{OH}-\mathrm{C} 10$ & & Glu & Thr & Ile & Leu & Ser & Leu & Ser & Ile & $\ldots$ \\
\hline
\end{tabular}

${ }^{\mathrm{a}} \mathrm{FA}$ and $\mathrm{AA}$ in bold indicate differences in $\mathrm{RE}^{*} 1-1-14$

\section{BERETTA}

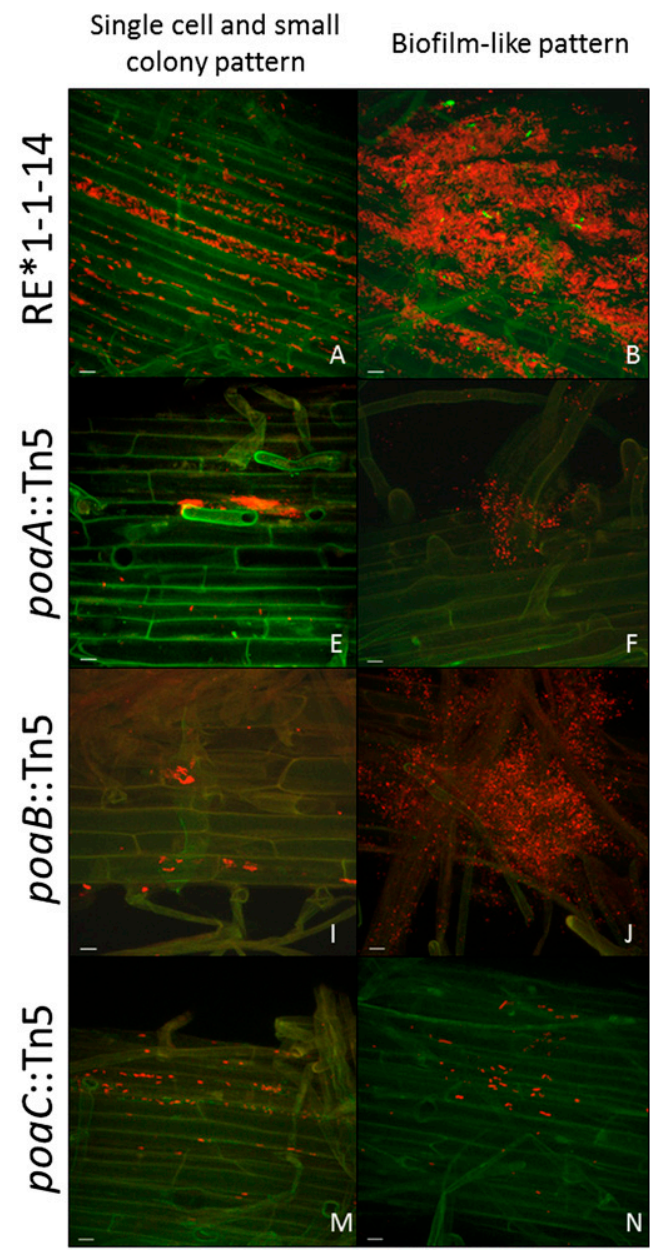

\section{JENNA}

Single cell and small Biofilm-like pattern
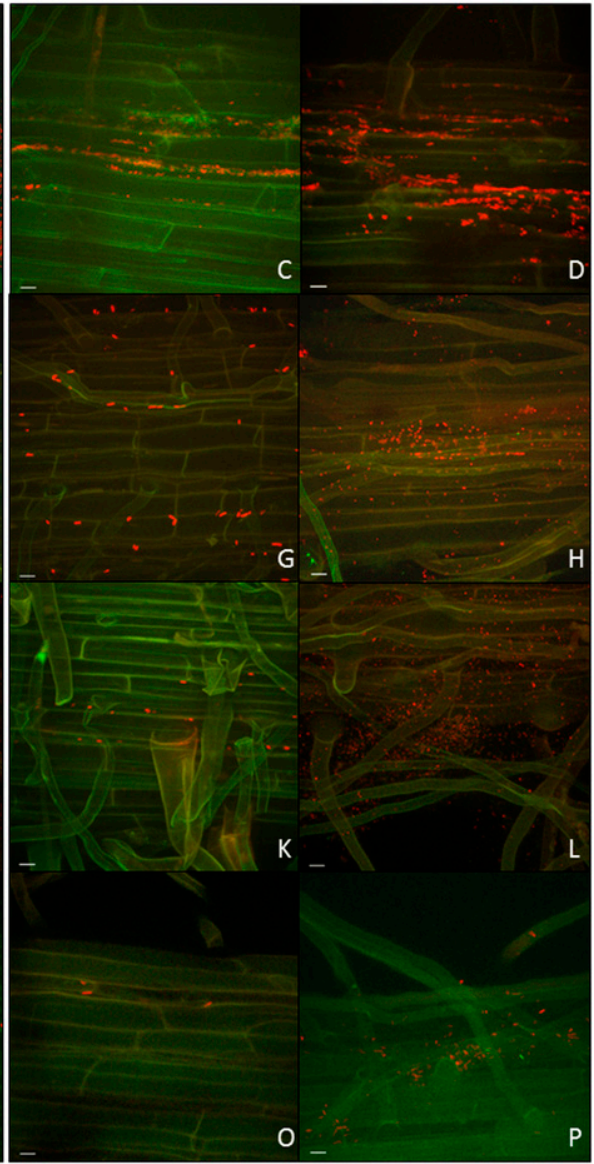

Fig. 7. Confocal laser-scanning microscopy of sugar beet cultivars Beretta (left panel, columns 1 and 2) and Jenna (right panel, columns 3 and 4 ). Seed were cultivated in germination pouches for 2 weeks and inoculated with DsRed-labeled Pseudomonas poae RE*1-1-14 wild type (row 1) and poaeamide-deficient mutants poaA::Tn5 (row 2), poaB::Tn5 (row 3), and poaC::Tn5 (row 4). Two colonization patterns were visualized for both cultivars: single cells or smal colonies in $\mathbf{A}, \mathbf{E}$, I, and $\mathbf{M}$, for Beretta and in $\mathbf{C}, \mathbf{G}, \mathbf{K}$, and $\mathbf{O}$, for Jenna; and biofilm-like network arrangements of the cells in $\mathbf{B}, \mathbf{F}, \mathbf{J}$, and $\mathbf{N}$, for Beretta and in $\mathbf{D}, \mathbf{H}, \mathbf{L}$ and $\mathbf{P}$, for Jenna. Scale bars represent $10 \mu \mathrm{m}$. 
qualitative colonization patterns. In our microscopic analyses, the poaeamide mutants showed fewer single cells attached to the plant roots, and the dimensions and the network constitution in the biofilm-like pattern showed a rather scattered colonization. In comparison, the wild type was observed to be organized in denser and more compact, biofilm-like structures, revealing a robust attachment to the plant roots and indicating that poaeamide is involved in attachment and settlement on plant root surfaces. The recent study of D'aes et al. (2014) suggested an influence of the CLPs on the ability to form biofilms in the plant-associated Pseudomonas sp. CMR12a. Cell density and, more importantly, the spatial distribution of cells are critical in regulating particular factors and exerting a certain lifestyle in a population-densitydependent manner, which is known as quorum sensing (QS) (Hense et al. 2007; Liu et al. 2011). QS-mediated control of mechanisms in plant-associated microorganisms have been reported for Pseudomonas, Stenotrophomonas, and Serratia spp. (Alavi et al. 2013; de Bruijn et al. 2008; Liu et al. 2011; Müller et al. 2009; Song et al. 2014). The genome of RE*1-1-14 contains a homolog gene of $h d t S$, which putatively encoding the synthase of the QS molecule $N$-dodecanoyl-L-homoserine lactone (DHL) in $P$. fluorescens F113 and P. fluorescens SBW25 (Laue et al. 2000; Moshynets et al. 2014). In the latter strain, an increased concentration of DHL has been shown to enhance biofilm thickness (Moshynets et al. 2014). The wild type of RE*1-1-14 is able to form dense colonies, presumably resulting in accumulation of autoinducers and induction (e.g., increased synthesis of extracellular polysaccharides) of particular factors, which facilitates settlement in biofilms (Eberl et al. 2007; Moshynets et al. 2014; Wei and Zhang 2006). The regulatory mechanisms at locally high cell density promotes biofilm formation on the root surface (Fig. 7) but prevents further spread, which may explain the lower number of CFU found for the wild type (Fig. 6). Thus, the microscopically observed more dense and compact biofilm-like colonization of the wild type compared with the mutants could make it more difficult to accurately estimate the number of cells based on CFU due to stronger adherence, possible clumping, or aggregation leading to an underestimation of the actual cell number present. Taken together, the scattered root colonization and the high overall cell counts of the mutants suggest that poaeamide may be necessary for initial adherence to trigger biofilm formation that subsequently affects cell-to-cell communication and density-dependent expression of genes with the endophytic lifestyle.

\section{MATERIAL AND METHODS}

\section{Genome analysis-Identification and phylogeny of NRPS genes and domains.}

For identification of putative NRPS genes involved in LP synthesis, the genes annotated as in the genome of $P$. poae $\mathrm{RE}^{*} 1-1-14$ were used in BlastP comparisons with wholegenome sequences of Pseudomonas spp. available in the Pseudomonas genome databases. The PFAM sequence search and the PKS/NRPS analysis were used for cluster and structure analysis of the A, T, C, and TE domains of the predicted NRPS genes. For phylogenetic analyses, alignments were made with CLUSTALX (version 1.81). Trees were inferred by neighbor joining in CLUSTALX using 10,000 bootstrap replicates. The peptide moiety of the putative LP signature sequences were identified in the A domains, as described by Stachelhaus et al. (1999) and Challis et al. (2000).

\section{Surfactant production assay and surface tension measurement.}

To test culture supernatants for biosurfactant activity, overnight cultures grown in NBII (Sifin, Berlin) and King's B (KB) medium (per liter: $20 \mathrm{~g}$ of proteose peptone, $1.5 \mathrm{~g}$ of $\mathrm{MgSO}_{4} \times 7$ $\mathrm{H}_{2} \mathrm{O}, 1.2 \mathrm{~g}$ of $\mathrm{KH}_{2} \mathrm{PO}_{4}$, and $10 \mathrm{~g}$ of glycerol) were used according to Kuiper et al. (2004). Briefly, after the addition of $5 \%$ methylene blue (which is useful for photography but has no influence on droplet surface tension), 20 and $50 \mu$ were pipetted as a droplet onto parafilm. The spreading of the droplet on the parafilm was observed, the droplet was allowed to dry, and the diameter of the dried droplet was recorded. Measurements of this diameter are in millimeters and represent means of at least two experiments. Surface tension measurements with pure compounds were carried out with a K6 tensiometer (Krüss $\mathrm{GmbH}$, Hamburg, Germany) and were performed at $25^{\circ} \mathrm{C}$.

\section{Extraction and chemical identification}

of the poaeamide produced by $P$. poae $\mathrm{RE}^{* 1-1-14}$.

P. poae $\mathrm{RE}^{*} 1-1-14$ was grown on $\mathrm{KB}$ medium for $48 \mathrm{~h}$ at $25^{\circ} \mathrm{C}$ and the crude poaeamide was extracted as described by de Bruijn et al. (2007). Analytical HPLC separations were carried out according to de Bruijn et al. (2008). Prior to the chiral analyses, poaeamide was purified using RP-HPLC, employing a linear gradient of $50: 50$ to $100: 0$ methanol $/ \mathrm{H}_{2} \mathrm{O}(0.1 \%$ trifluoroacetic acid) over a period of $30 \mathrm{~min}$, followed by isocratic elution at $100 \%$ methanol for an additional $10 \mathrm{~min}$ (column: Phenomenex Kinetex XB-C18, 4.6 by $250 \mathrm{~mm}, 1 \mathrm{ml}$ $\min ^{-1}$ flow rate, and UV monitoring at $215 \mathrm{~nm}$ ). Poaeamide eluted under these conditions after $R_{\mathrm{t}}=32.5 \mathrm{~min}$. All solvents were purchased as HPLC grade. Details about the employed spectroscopic instruments and methods, chiral HPLC-MS analysis of the 3-HDA portion of poaeamide A, chiral GCMS analysis of poaeamide A, partial degradation of poaeamide A by enzymatic, and acid hydrolysis are described in the corresponding description parts in the supplementary materials.

\section{Mutagenesis of $P$. poae $\mathrm{RE}^{*}$ 1-1-14 and DsRed transformation.}

P. poae $\mathrm{RE}^{*} 1-1-14$ was subjected to random plasposon mutagenesis with ppKm-laci plasmid modified from Choi et al. (2006). Transformants were screened for single insertions by Southern blot analysis using the kanamycin resistance gene as a probe. Single insertion mutants were screened for surfactant production by resuspending cells from agar plate cultures in sterile demineralized water to a density of approximately $10^{9}$ cells $\mathrm{ml}^{-1}$ followed by a drop-collapse assay on parafilm. Plasmid rescue from the putative mutants and sequence analysis of the regions flanking the plasposon were performed according to the methods described by Dennis and Zylstra (1998). Transformation with a rhizosphere-stable plasmid containing DsRed gene was performed for the wild type and poaeamide mutants according to Zachow et al. (2010).

\section{Southern hybridization.}

Southern blot analysis was performed to determine the number of integrations of the Tn5lacZKm element in the surfactant-deficient mutants of $P$. poae strain RE*1-1-14. Genomic DNA of the mutants was digested with $5 \mathrm{U}$ of Pst $\mathrm{I}$ (Promega, Leiden, The Netherlands), an enzyme without restriction sites in the Tn5lacZKm element (de Lorenzo et al. 1990). The digestions were performed in a total volume of $100 \mu \mathrm{l}$ containing $1.0 \mu \mathrm{g}$ of DNA. The digested DNA was precipitated with 2.5 volumes of $99 \%$ ethanol and $1 / 10$ volume of $3 \mathrm{M}$ sodium acetate, washed with $70 \%$ ethanol, dissolved in $15 \mu \mathrm{l}$ of sterile distilled water, and separated on $1 \%$ agarose gels in $1 \times$ Tris-acetate-EDTA $(13 \mathrm{~h}, 35 \mathrm{~V})$. DNA transfer from agarose gels to Hybond $\mathrm{N}$ nylon membranes (Amersham Pharmacia Biotech) was performed according to standard methods (Sambrook and Russell 2001). The high-stringency conditions consisted of prehybridization for $1 \mathrm{~h}$ at $65^{\circ} \mathrm{C}$, 
hybridization for $12 \mathrm{~h}$ at $65^{\circ} \mathrm{C}$, and membrane washings: twice each for $5 \mathrm{~min}$ with $2 \times \mathrm{SSC}(1 \times \mathrm{SSC}$ is $0.15 \mathrm{M} \mathrm{NaCl}$ plus $0.015 \mathrm{M}$ sodium citrate) plus $0.1 \%$ sodium dodecyl sulfate (SDS) at room temperature and twice each for $20 \mathrm{~min}$ with $0.1 \times$ SSC plus $0.1 \%$ SDS at $65^{\circ} \mathrm{C}$. The 800 -bp kanamycin probe, specific for the kanamycin resistance gene contained within the Tn5LacZKm element, was obtained by digoxigenin labeling using primers Kmf (5'-GGAAACGTCTTGCTCGAGG-3') and $\mathrm{Kmr}$ (5'-TCGAGCATCAAATGAAACTGC-3') (Biolegio, Nijmegen, The Netherlands); hybridized probes were immunodetected with the polymerase chain reaction dig labeling mix according to the protocols provided by the supplier (Roche, Mannheim, Germany).

\section{Activity assays-Zoospore lysis, and antioomycete and antifungal activity.}

Zoospores were obtained from Phytophthora infestans strain 88069 grown on rye sucrose agar (RSA) (Caten and Jinks 1968) for 10 days at $18^{\circ} \mathrm{C}$ and from P. capsici LT3239 grown on V8 agar for 7 days at $25^{\circ} \mathrm{C}$ under lab light. Plates were flooded with sterile distilled water and incubated at $4^{\circ} \mathrm{C}$. After $4 \mathrm{~h}$, $P$. infestans zoospores were collected and exposed to cell-free supernatant of Pseudomonas poae RE*1-1-14 wild type, poaA:: Tn5, poaB::Tn5, and poaC::Tn5 mutants or to a concentration series of the crude poaeamide of $P$. poae RE*1-1-14, which was obtained as described by de Bruijn et al. (2007). After $30 \mathrm{~min}$, Phytophthora capsici LT3239 plates were incubated at room temperature for $1 \mathrm{~h}$ to release zoospores, which were exposed to cell-free supernatant as described. Zoospore behavior was observed microscopically.

The oomycete and fungal plant pathogens tested in these dualculture assays were $P$. capsici LT3239, P. infestans 88069 (grown on RSA instead of Waksman agar), Pythium ultimum, and $R$. solani AG2-2IIIB. Zones of inhibition were measured according to Berg et al. 2005 and the experiments were repeated twice. Phytophthora capsici strain LT3239, originally isolated from pumpkin, was routinely grown at $25^{\circ} \mathrm{C}$ on V8 juice medium (V8; N.V. Campbell Foods Puurs, Belgium) amended with $\mathrm{CaCO}_{3}$ at $3 \mathrm{~g} \mathrm{liter}^{-1}$ and agar at $15 \mathrm{~g} \mathrm{liter}^{-1}$. The other phytopathogenic strains used in the experiments are stock material of the Laboratory of Phytopathology (Wageningen University).

\section{Ecological functioning assays-swarming motility.}

Motility and swarming was analyzed according to the protocol described by de Bruijn et al. (2008). Briefly, overnight cultures of Pseudomonas poae RE*1-1-14 and the mutants were washed three times with sterile $0.85 \% \mathrm{NaCl}$. Each cell suspension $(5 \mu \mathrm{l}$ of $10^{9}$ cells $\mathrm{ml}^{-1}$ ) were spotted in the center of soft (motility, $0.6 \%$ agar [wt/vol] and swarming, $0.2 \%$ agar [wt/vol]) standard succinate medium, consisting of $32.8 \mathrm{mM} \mathrm{K} \mathrm{HPO}_{4}, 22 \mathrm{mM}$ $\mathrm{KH}_{2} \mathrm{PO}_{4}, 7.6 \mathrm{mM}\left(\mathrm{NH}_{4}\right)_{2} \mathrm{SO}_{4}, 0.8 \mathrm{mM} \mathrm{MgSO}$, and $34 \mathrm{mM}$ succinic acid, adjusted $\mathrm{pH}$ to 7 with $\mathrm{NaOH}$. Agar plates were incubated for $48 \mathrm{~h}$ to $72 \mathrm{~h}$ at $25^{\circ} \mathrm{C}$.

\section{Biofilm.}

Biofilm formation was assessed according to the method described by de Bruijn et al. (2008). Briefly, in a flat-bottom 96well plate made of transparent polystyrene (Greiner), $200 \mu \mathrm{l}$ of $\mathrm{KB}$ medium per well was inoculated with $20 \mu \mathrm{l}$ of a suspension containing $10^{9}$ cell ml ${ }^{-1}$. Plates were sealed and incubated at 15 , 20,25 , and $30^{\circ} \mathrm{C}$. After 24 and $48 \mathrm{~h}$, the plates were incubated for 15 min with $10 \mu \mathrm{l}$ of $0.1 \%$ crystal violet per well. Wells were washed three times with distilled water and remaining biofilms with crystal violet were dissolved in $200 \mu \mathrm{l}$ of $96 \%$ ethanol per well. Biofilm formation was measured at an optical density of $600 \mathrm{~nm}$. Statistically significant differences were determined with Student's $t$ test $(P \leq 0.05)$. Massetolide-A-producing strain $P$. fluorescens SS101 (De Souza et al. 2003) was used as a reference.

\section{Colonization.}

Sugar beet seed of Beretta KWS and Jenna KWS were inoculated $\left(4 \mathrm{~h}\right.$ under agitation, $\left.25^{\circ} \mathrm{C}\right)$ in DsRed-labeled $P$. poae RE*1-1-14 and poaeamide-deficient mutants poaA::Tn5, poaB:: Tn5, and poaC::Tn5 at $1 \times 10^{9}$ cells $\mathrm{ml}^{-1}$. Sugar beet seed were cultivated under gnotobiotic conditions in germination pouches (Mega International, Minneapolis, MN, U.S.A.) according to the manufacturer's instructions and cultivated at $25^{\circ} \mathrm{C}$ in a regime of $16 \mathrm{~h}$ of light and $8 \mathrm{~h}$ of darkness and filled with sterile tap water. After 2 weeks, the germinated plants were removed for microscopic and cultivation analyses. For the latter, roots were harvested and grounded with sterile $0.85 \%$ sodium chloride and dilutions were spread on NBII agar plates amended with appropriate concentration of tetracycline $\left(40 \mu \mathrm{g} \mathrm{ml}^{-1}\right)$ and kanamycin $\left(50 \mu \mathrm{g} \mathrm{ml}^{-1}\right.$ ) for determination of CFU per gram fresh weight. For determination of endophytic (upper layer of the cortex under the epidermal cell layer) colonization, roots were harvested in $2.5 \mathrm{ml}$ of sterile $0.85 \% \mathrm{NaCl}$ amended with $0.02 \%$ sterile Tween40 (Sigma-Aldrich, Vienna). To get bacteria from endophytic root habitat and the cortex, roots were washed with 10 consecutive cycles of sonication for 1 min (ELMA Ultrasonics LC-130H, Singen, Germany) and were subsequently vigorously vortexed. The washed roots were transferred to a new tube containing $2.5 \mathrm{ml}$ of sterile $0.85 \% \mathrm{NaCl}$ amended with Tween 40 (all steps at $4^{\circ} \mathrm{C}$ ), before grounding with $2 \mathrm{ml}$ of $0.85 \% \mathrm{NaCl}$. Dilutions were spread on NBII agar amended with antibiotics. CFU were determined for both cultivars in four replicates each.

Colonization pattern of transformed bacteria on seedling roots were monitored in depth using a Leica TCS SP CLSM (Leica Microsystems, Wetzlar, Germany) equipped with argon and helium/neon lasers. Two confocal light channels were observed simultaneously. Filter settings were adjusted to achieve the maximum signal from the DsRed protein and low background autofluorescence of the plant tissue with an excitation of $563 \mathrm{~nm}$ and an emission of $582 \mathrm{~nm}$. Maximum projections of an appropriate number of $0.8-\mu \mathrm{m}$-deep optical slices were applied to visualize the root sections (confocal stacks). Up to three scans per optical slice were averaged to improve the image resolution and to reduce noise. Single TIFF snapshots were processed with ImageJ (Schneider et al. 2012) and imported in Microsoft Office PowerPoint to be assembled and labeled.

\section{Bioinformatic analysis.}

The amino acid sequences of the NRPSs involved in poaeamide biosynthesis were compared and analyzed with NRPS-PKS webbased software (National Institute of Immunology) (Ansari et al. 2004) and antiSMASH (Blin et al. 2013). Multiple alignments were performed using the MEGA6 according to Tamura et al. (2013). Phylogenetic trees were visualized with Drawtree, MEGA6, or geneious R7.

\section{ACKNOWLEDGMENTS}

We thank N. C. A. de Ruijter (Wageningen University) for technical advices of in slide microscopy; A. Steck (Analytical Services \& Applied NMR Development at Bruker Biospin $\mathrm{GmbH}$ ) for generous support and NMR measurements; D. Wistuba and her team (Mass Spectrometry Department, Institute for Organic Chemistry, University of Tuebingen) for HRMS measurements; the Struktur- und Innovationsfonds Baden-Württemberg (SI-BW) and the German Research Foundation DFG for support of H. Gross (GR26473/2-1) and M. Lämmerhofer regarding funding of scientific equipment as part of the DFG's Major Research Instrumentation Programme (as per Art. 91b GG; INST 37/821-1 FUGG), respectively; and K. H. Lamour (University of Tennessee, Knoxville, TN, U.S.A.) for providing Phytophthora capsici LT3239. G. Jahanshah gratefully acknowleges a Ph.D. fellowship 
from the German Academic Exchange Service (DAAD). This work was funded by the Austrian Centre of Industrial Biotechnology, which has been supported by the Austrian BMWFJ, BMVIT, SFG, Standortagentur Tirol, and ZIT through the Austrian FFG-COMET-Funding Program. Seed materials were kindly provided from KWS SAAT AG (Einbeck, Germany).

\section{LITERATURE CITED}

Alavi, P., Müller, H., Cardinale, M., Zachow, C., Sánchez, M. B., Martínez, J. L., and Berg, G. 2013. The DSF quorum sensing system controls the positive influence of Stenotrophomonas maltophilia on plants. PLoS One 8:e67103.

Ansari, M. Z., Yadav, G., Gokhale, R. S., and Mohanty, D. 2004. NRPSPKS: A knowledge-based resource for analysis of NRPS/PKS megasynthases. Nucleic Acids Res. 32:W405-W413.

Bais, H. P., Fall, R., and Vivanco, J. M. 2004. Biocontrol of Bacillus subtilis against infection of Arabidopsis roots by Pseudomonas syringae is facilitated by biofilm formation and surfactin production. Plant Physiol. 134:307-319.

Balibar, C. J., Vaillancourt, F. H., and Walsh, C. T. 2005. Generation of D amino acid residues in assembly of arthrofactin by dual condensation/epimerization domains. Chem. Biol. 12:1189-1200.

Behrendt, U., Ulrich, A., and Schumann, P. 2003. Fluorescent pseudomonads associated with the phyllosphere of grasses; Pseudomonas trivialis sp. nov., Pseudomonas poae sp. nov. and Pseudomonas congelans sp. nov. Int. J. Syst. Evol. Microbiol. 53:1461-1469.

Berg, G., Krechel, A., Ditz, M., Sikora, R. A., Ulrich, A., and Hallmann, J 2005. Endophytic and ectophytic potato-associated bacterial communities differ in structure and antagonistic function against plant pathogenic fungi. FEMS Microbiol. Ecol. 51:215-229.

Blin, K., Medema, M. H., Kazempour, D., Fischbach, M. A., Breitling, R., Takano, E., and Weber, T. 2013. antiSMASH 2.0-A versatile platform for genome mining of secondary metabolite producers. Nucleic Acids Res. 41:W204-W212.

Bode, H. B. 2009. Entomopathogenic bacteria as a source of secondary metabolites. Curr. Opin. Chem. Biol. 13:224-230.

Caten, C. E., and Jinks, J. L. 1968. Spontaneous variability of single isolates of Phytophthora infestans. I. Cultural variation. Can. J. Bot. 46:329-348.

Challis, G. L., Ravel, J., and Townsend, C. A. 2000. Predictive, structurebased model of amino acid recognition by nonribosomal peptide synthetase adenylation domains. Chem. Biol. 7:211-224.

Choi, K. H., Kumar, A., and Schweizer, H. P. 2006. A 10-min method for preparation of highly electrocompetent Pseudomonas aeruginosa cells: Application for DNA fragment transfer between chromosomes and plasmid transformation. J. Microbiol. Methods 64:391-397.

D’aes, J., Kieu, N. P., Léclère, V., Tokarski, C., Olorunleke, F. E., De Maeyer, K., Jacques, P., Höfte, M., and Ongena, M. 2014. To settle or to move? The interplay between two classes of cyclic lipopeptides in the biocontrol strain Pseudomonas CMR12a. Environ. Microbiol. 16:2282-2300.

de Bruijn, I., de Kock, M. J., Yang, M., de Waard, P., van Beek, T. A., and Raaijmakers, J. M. 2007. Genome-based discovery, structure prediction and functional analysis of cyclic lipopeptide antibiotics in Pseudomonas species. Mol. Microbiol. 63:417-428.

de Bruijn, I., de Kock, M. J. D., de Waard, P., van Beek, T. A., and Raaijmakers, J. M. 2008. Massetolide A biosynthesis in Pseudomonas fluorescens. J. Bacteriol. 190:2777-2789.

de Lorenzo, V., Herrero, M., Jakubzik, U., and Timmis, K. N. 1990. MiniTn5 transposon derivatives for insertion mutagenesis, promoter probing, and chromosomal insertion of cloned DNA in gram-negative eubacteria. J. Bacteriol. 172:6568-6572.

Dennis, J. J., and Zylstra, G. J. 1998. Plasposons: Modular self-cloning minitransposon derivatives for rapid genetic analysis of gram-negative bacterial genomes. Appl. Environ. Microbiol. 64:2710-2715.

De Souza, J. T., De Boer, M., De Waard, P., Van Beek, T. A., and Raaijmakers, J. M. 2003. Biochemical, genetic, and zoosporicidal properties of cyclic lipopeptide surfactants produced by Pseudomonas fluorescens. Appl. Environ. Microbiol. 69:7161-7172.

Eberl, L., von Bodman, S. B., and Fuqua, C. 2007. Biofilms on plant surfaces. Pages 215-234 in: The Biofilm Mode of Life: Mechanisms and Adaptations, Vol. 12. Horizon Bioscience, Norfolk.

Gross, H., and Loper, J. E. 2009. Genomics of secondary metabolite production by Pseudomonas spp. Nat. Prod. Rep. 26:1408-1446.

Gross, H., Stockwell, V. O., Henkels, M. D., Nowak-Thompson, B., Loper, J. E., and Gerwick, W. H. 2007. The genomisotopic approach: A systematic method to isolate products of orphan biosynthetic gene clusters. Chem. Biol. 14:53-63.

Hense, B. A., Kuttler, C., Müller, J., Rothballer, M., Hartmann, A., and Kreft, J. U. 2007. Does efficiency sensing unify diffusion and quorum sensing? Nat. Rev. Microbiol. 5:230-239.
Hou, J., Robbel, L., and Marahiel, M. A. 2011. Identification and characterization of the lysobactin biosynthetic gene cluster reveals mechanistic insights into an unusual termination module architecture. Chem. Biol. 18:655-664

Huang, X., Gaballa, A., Cao, M., and Helmann, J. D. 1999. Identification of target promoters for the Bacillus subtilis extracytoplasmic function $\sigma$ factor, $\sigma$ W. Mol. Microbiol. 31:361-371.

Ianni, F., Pataj, Z., Gross, H., Sardella, R., Natalini, B., Lindner, W., and Lämmerhofer, M. 2014. Direct enantioseparation of underivatized aliphatic 3-hydroxyalkanoic acids with a quinine-based zwitterionic chiral stationary phase. J. Chromatogr. A 1363:101-108.

Imker, H. J., Krahn, D., Clerc, J., Kaiser, M., and Walsh, C. T. 2010 $N$-acylation during glidobactin biosynthesis by the tridomain nonribosomal peptide synthetase module GlbF. Chem. Biol. 17:1077-1083

Kalb, D., Lackner, G., and Hoffmeister, D. 2013. Fungal peptide synthetases: An update on functions and specificity signatures. Fungal Biol. Rev. 27:43-50.

Kim, B. S., Lee, J. Y., and Hwang, B. K. 2000. In vivo control and in vitro antifungal activity of rhamnolipid B, a glycilipid antibiotic, agains Phytophthora capsici and Colletotrichum orbiculare. Pest Manag. Sci. 56:1029-1035.

Kraas, F. I., Helmetag, V., Wittmann, M., Strieker, M., and Marahiel, M. A. 2010. Functional dissection of surfactin synthetase initiation module reveals insights into the mechanism of lipoinitiation. Chem. Biol. 17: 872-880.

Kruijt, M., Tran, H., and Raaijmakers, J. M. 2009. Functional, genetic and chemical characterization of biosurfactants produced by plant growthpromoting Pseudomonas putida 267. J. Appl. Microbiol. 107:546-556.

Kuiper, I., Lagendijk, E. L., Pickford, R., Derrick, J. P., Lamers, G. E., Thomas-Oates, J. E., Lugtenberg, B. J. J., and Bloemberg, G. V. 2004 Characterization of two Pseudomonas putida lipopeptide biosurfactants, putisolvin I and II, which inhibit biofilm formation and break down existing biofilms. Mol. Microbiol. 51:97-113.

Lange, A., Sun, H., Pilger, J., Reinscheid, U. M., and Gross, H. 2012. Predicting the structure of cyclic lipopeptides by bioinformatics: Structure revision of arthrofactin. ChemBioChem 13:2671-2675.

Laue, B. E., Jiang, Y., Chhabra, S. R., Jacob, S., Stewart, G. S., Hardman, A., Downie, J. A., O'Gara, F., and Williams, P. 2000. The biocontrol strain Pseudomonas fluorescens F113 produces the Rhizobium small bacteriocin, $N$-(3-hydroxy-7-cis-tetradecenoyl)homoserine lactone, via HdtS, a putative novel $N$-acylhomoserine lactone synthase. Microbiology 146:2469-2480.

Li, W., Rokni-Zadeh, H., De Vleeschouwer, M., Ghequire, M. G. K., Sinnaeve, D., Xie, G.-L., Rozenski, J., Madder, A., Martins, J. C., and De Mot, R. 2013. The antimicrobial compound xantholysin defines a new group of Pseudomonas cyclic lipopeptides. PLoS One 8:e62946.

Liu, X., Jia, J., Popat, R., Ortori, C. A., Li, J., Diggle, S. P., Gao, K., and Cámara, M. 2011. Characterisation of two quorum sensing systems in the endophytic Serratia plymuthica strain G3: Differential control of motility and biofilm formation according to life-style. BMC Microbiol. 11:26.

Loper, J. E., and Gross, H. 2007. Genomic analysis of antifungal metabolite production by Pseudomonas fluorescens Pf-5. Eur. J. Plant Pathol. 119: 265-278.

Loper, J. E., Hassan, K. A., Mavrodi, D. V., Davis, E. W., 2nd, Lim, C. K., Shaffer, B. T., Elbourne, L. D. H., Stockwell, V. O., Hartney, S. L., Breakwell, K., Henkels, M. D., Tetu, S. G., Rangel, L. I., Kidarsa, T. A. Wilson, N. L., van de Mortel, J. E., Song, C., Blumhagen, R., Radune, D., Hostetler, J. B., Brinkac, L. M., Durkin, A. S., Kluepfel, D. A., Wechter, W. P., Anderson, A. J., Kim, Y. C., Pierson, L. S., 3rd, Pierson, E. A. Lindow, S. E., Kobayashi, D. Y., Raaijmakers, J. M., Weller, D. M. Thomashow, L. S., Allen, A. E., and Paulsen, I. T. 2012. Comparative genomics of plant-associated Pseudomonas spp.: Insights into diversity and inheritance of traits involved in multitrophic interactions. PLoS Genet. 8:e1002784.

Mark, G. L., Dow, J. M., Kiely, P. D., Higgins, H., Haynes, J., Baysse, C., Abbas, A., Foley, T., Franks, A., Morrissey, J., and O'Gara, F. 2005 Transcriptome profiling of bacterial responses to root exudates identifies genes involved in microbe-plant interactions. Proc. Natl. Acad. Sci. U.S.A 102:17454-17459.

Meyer, J. B., Lutz, M. P., Frapolli, M., Péchy-Tarr, M., Rochat, L., Keel, C., Défago, G., and Maurhofer, M. 2010. Interplay between wheat cultivars, biocontrol pseudomonads, and soil. Appl. Environ. Microbiol. 76: 6196-6204.

Moshynets, O., Rogalsky, S., Pokholenko, J., Irodov, D., Kararhim, S., and Spiers, A. J. 2014. Pseudomonas fluorescens SBW25 reveals AHL dependent quorum sensing behaviour in culture and biofilms. Poster presented at Biofilm 6 Conf. Vienna. 
Mulet, M., Lalucat, J., and García-Valdés, E. 2010. DNA sequence-based analysis of the Pseudomonas species. Environ. Microbiol. 12:1513-1530.

Müller, H., Westendorf, C., Leitner, E., Chernin, L., Riedel, K., Schmidt, S., Eberl, L., and Berg, G. 2009. Quorum-sensing effects in the antagonistic rhizosphere bacterium Serratia plymuthica HRO-C48. FEMS Microbiol. Ecol. 67:468-478.

Müller, H., Zachow, C., Alavi, M., Tilcher, R., Krempl, P. M., Thallinger, G. G., and Berg, G. 2013. Complete genome sequence of the sugar beet endophyte Pseudomonas poae RE* 1-1-14, a disease-suppressive bacterium. Genome Announce. 1:e00020-13.

Nielsen, T. H., Nybroe, O., Koch, B., Hansen, M., and Sørensen, J. 2005. Genes involved in cyclic lipopeptide production are important for seed and straw colonization by Pseudomonas sp. strain DSS73. Appl. Environ. Microbiol. 71:4112-4116.

Pauwelyn, E., Huang, C. J., Ongena, M., Leclère, V., Jacques, P., Bleyaert, P., Budzikiewicz, H., Schäfer, M., and Höfte, M. 2013. New linear lipopeptides produced by Pseudomonas cichorii SF1-54 are involved in virulence, swarming motility, and biofilm formation. Mol. PlantMicrobe Interact. 26:585-598.

Peiffer, J. A., Spor, A., Koren, O., Jin, Z., Tringe, S. G., Dangl, J. L., Buckler, E. S., and Ley, R. E. 2013. Diversity and heritability of the maize rhizosphere microbiome under field conditions. Proc. Natl. Acad. Sci. U.S.A. 110:6548-6553.

Raaijmakers, J. M., de Bruijn, I., Nybroe, O., and Ongena, M. 2010. Natural functions of lipopeptides from Bacillus and Pseudomonas: More than surfactants and antibiotics. FEMS Microbiol. Rev. 34:1037-1062.

Raaijmakers, J. M., and Mazzola, M. 2012. Diversity and natural functions of antibiotics produced by beneficial and plant pathogenic bacteria. Annu. Rev. Phytopathol. 50:403-424.

Rainey, P. B., and Bailey, M. J. 1996. Physical and genetic map of the Pseudomonas fluorescens SBW25 chromosome. Mol. Microbiol. 19:521-533.

Rausch, C., Hoof, I., Weber, T., Wohlleben, W., and Huson, D. H. 2007. Phylogenetic analysis of condensation domains in NRPS sheds light on their functional evolution. BMC Evol. Biol. 7:78.

Rokni-Zadeh, H., Li, W., Sanchez-Rodriguez, A., Sinnaeve, D., Rozenski, J., Martins, J. C., and De Mot, R. 2012. Genetic and functional characterization of cyclic lipopeptide white-line-inducing principle (WLIP) production by rice rhizosphere isolate Pseudomonas putida RW10S2. Appl. Environ. Microbiol. 78:4826-4834.

Roongsawang, N., Washio, K., and Morikawa, M. 2007. In vivo characterization of tandem C-terminal thioesterase domains in arthrofactin synthetase. ChemBioChem 8:501-512.

Sambrook, J., and Russell, D. W. 2001. Molecular Cloning: A Laboratory Manual, 3rd ed. Cold Spring Harbor Laboratory Press, Cold Spring Harbor, NY, U.S.A.

Schneider, C. A., Rasband, W. S., and Eliceiri, K. W. 2012. NIH Image to ImageJ: 25 years of image analysis. Nat. Meth. 9:671-675.
Schwarzer, D., Mootz, H. D., Linne, U., and Marahiel, M. A. 2002. Regeneration of misprimed nonribosomal peptide synthetases by type II thioesterases. Proc. Natl. Acad. Sci. U.S.A. 99:14083-14088.

Song, C., Aundy, K., van de Mortel, J., and Raaijmakers, J. M. 2014. Discovery of new regulatory genes of lipopeptide biosynthesis in Pseudomonas fluorescens. FEMS Microbiol. Lett. 356:166-175.

Stachelhaus, T., Mootz, H. D., and Marahiel, M. A. 1999. The specificityconferring code of adenylation domains in nonribosomal peptide synthetases. Chem. Biol. 6:493-505.

Tamura, K., Stecher, G., Peterson, D., Filipski, A., and Kumar, S. 2013. MEGA6: Molecular evolutionary genetics analysis version 6.0. Mol. Biol. Evol. 30:2725-2729.

Tran, H., Ficke, A., Asiimwe, T., Höfte, M., and Raaijmakers, J. M. 2007. Role of the cyclic lipopeptide massetolide A in biological control of Phytophthora infestans and in colonization of tomato plants by Pseudomonas fluorescens. New Phytol. 175:731-742.

Vallet-Gely, I., Novikov, A., Augusto, L., Liehl, P., Bolbach, G., PéchyTarr, M., Cosson, P., Keel, C., Caroff, M., and Lemaitre, B. 2010 Association of hemolytic activity of Pseudomonas entomophila, a versatile soil bacterium, with cyclic lipopeptide production. Appl. Environ. Microbiol. 76:910-921.

Wei, H. L., and Zhang, L. Q. 2006. Quorum-sensing system influences root colonization and biological control ability in Pseudomonas fluorescens 2P24. Antonie van Leeuwenhoek 89:267-280.

Yeh, E., Kohli, R. M., Bruner, S. D., and Walsh, C. T. 2004. Type II thioesterase restores activity of a NRPS module stalled with an aminoacyl-S-enzyme that cannot be elongated. ChemBioChem 5: 1290-1293.

Zachow, C., Fatehi, J., Cardinale, M., Tilcher, R., and Berg, G. 2010. Strainspecific colonization pattern of Rhizoctonia antagonists in the root system of sugar beet. FEMS Microbiol. Ecol. 74:124-135.

Zachow, C., Tilcher, R., and Berg, G. 2008. Sugar beet-associated bacterial and fungal communities show a high indigenous antagonistic potential against plant pathogens. Microb. Ecol. 55:119-129.

Ziemert, N., Podell, S., Penn, K., Badger, J. H., Allen, E., and Jensen, P. R. 2012. The natural product domain seeker NaPDoS: A phylogeny based bioinformatic tool to classify secondary metabolite gene diversity. PLoS One 7:e34064.

\section{AUTHOR-RECOMMENDED INTERNET RESOURCES}

CLUSTALX software: http://www.ebi.ac.uk/clustalw/ National Institute of Immunology: http://www.nii.res.in/ PFAM sequence search: http://pfam.sanger.ac.uk/search/sequence PKS/NRPS analysis: http://nrps.igs.umaryland.edu/nrps/ Pseudomonas genomes: www.pseudomonas.com Pseudomonas genome databases: http://v2.pseudomonas.com 